\title{
ANTE UN ESQUEMA DOLARIZADO PARA HONDURAS
}

\author{
Jorge Flores Silva*
}

DOI: $10.5377 /$ eya.v10i2.9090

Recibido: 4/2/2019 Aceptado: 5/3/2019

\section{RESUMEN}

Solo la economía puede fortalecer la moneda, la dolarización no oficial pero tolerada es un reflejo de la desconfianza que hay en la política cambiaria y monetaria que se ejecuta en el país. La incertidumbre por la devaluación genera desconfianza en la moneda nacional, es aquí cuando empresarios, comerciantes y otros sectores económicos empiezan a cotizar y a dolarizar bienes y servicios. Es por la desconfianza que se sustituye la moneda doméstica por la extranjera, en nuestro caso por el dólar, en la que distintas transacciones financieras que realiza la gente para obtener productos financieros, bienes o servicios tales como compras, alquileres, pago de colegiaturas, depósitos bancarios y otras operaciones se realizan en dólares. Cuando el fenómeno de la dolarización se somete al debate siempre se aborda única y exclusivamente desde la óptica financiera y monetaria, así se rehúye resaltar la visión estructural que hace ver la pérdida de valor de la moneda nacional como efecto de la débil economía. En la medida que se toquen y ataquen los aspectos que dan lugar a un aparato productivo débil y una estructura comercial distorsionada se podrá también fortalecer la moneda doméstica, y al mismo tiempo permitirá comprender más objetivamente la relación existente entre producción y función monetaria.

Palabras clave: devaluación, dolarización, tipo de cambio, política económica, divisa.

JEL: E42, E52

\footnotetext{
* Profesor del Instituto de Investigaciones Económicas y Sociales de la Facultad de Ciencias Económicas. Administrativas y Contables de la Universidad Nacional Autónoma de Honduras (UNAH). Correo electrónico: Jorge.flores@unah.edu.hn
} 


\title{
A DOLLARIZED SCHEME FOR HONDURAS
}

\author{
Jorge Flores Silva
}

DOI: $10.5377 /$ eya.v10i2.9090

\begin{abstract}
Only the economy can strengthen the currency, the unofficial but tolerated dollarization shows the distrust in the exchange and monetary policy that is executed in a country. Uncertainty about the devaluation creates distrust in the national currency. Entrepreneurs, merchants and other economic sectors begin to quote and set prices of goods and services in dollars. Mistrust causes the replacement of the domestic currency with a foreign currency. In the case of Honduras for the US dollar, in which different financial transactions that people make to obtain financial products, goods or services are made in dollars. When the issue of dollarization is subject to debate, it is always addressed only and exclusively from a financial and monetary point of view, the structural vision that makes the loss of value of the national currency as an effect of the weak economy is avoided. To the extent that the problems that generate a weak economic structure are also solved, the domestic currency can be strengthened, and at the same time it will allow a more objective understanding of the relationship between production and monetary function.
\end{abstract}

Keywords: devaluation, dollarization, exchange rate, economic policy, currency.

JEL: E42, E52 


\section{INTRODUCCIÓN}

El fenómeno de la dolarización se inscribe en el marco de la globalización, aunque el capital siempre ha tenido orientación internacional, es a partir de la caída del bloque socialista de Europa del este, que el concepto globalización cobra auge. La globalización y la ideología que la acompaña-el neoliberalismo- pone su acento en las relaciones comerciales para sustentar su avance y fundamentar el desarrollo. El mundo globalizado empuja con más fuerza los fundamentos del esquema dolarizado que empezó a dominar a partir de la conferencia monetaria y financiera de Bretton Woods. Es en esta conferencia que surge el sistema monetario internacional que hoy domina las economías de occidente, cuya influencia sobre todo el mundo es indiscutible, teniendo como centro del sistema el dólar.

La dolarización en Honduras, aunque no esté oficializada por la autoridad monetaria, ya se vive y experimenta en el país. Sus efectos se hacen sentir en los agentes económicos y en todos los elementos estructurales y variables económicas más importantes relacionadas con la producción, la inversión, el ingreso, el comercio internacional y el consumo.

Continuamente escuchamos quejas de la ciudadanía, de que algunos gastos e inversiones fijas las tienen que hacer en dólares o dicho de otra manera les están cobrando en dólares. Para nadie es extraño ver como algunas instituciones educativas realizan cobros de matrícula y colegiatura en dólares, lo mismo pasa con los alquileres de vivienda y apartamentos, la compra de vehículos y otros enseres domésticos. Son muchos los bienes y servicios cotizados con la moneda verde sin embargo en el país no se ha autorizado la dolarización oficial, pero es tolerada por la autoridad bajo el argumento de que el precio de la divisa está determinado por la oferta y demanda en el mercado. De esta manera sale perjudicado el ciudadano que recibe su pago en lempiras, en tanto que sus deudas se incrementan cuando tiene que pagar en dólares. Esto es así porque el Lempira periódica $y$ de manera muy frecuente se está depreciando y cualquier gasto que se realice en un bien o servicio dolarizado, el vendedor o acreedor automáticamente hace la conversión en dólares, cobra el equivalente en lempiras y el comprador o deudor también de manera automática tiene que dar más lempiras cuando realiza el pago. Todos los agentes económicos buscan blindarse de esta perversidad bajo el argumento de que se corre el riesgo de la devaluación periódica.

El único que no se escapa de este problema dolarización-devaluación es el asalariado y/o consumidor final que quiera o no, tiene que dar más lempiras por lo que paga o compra. 
Cuando este fenómeno de la dolarización se somete al debate siempre se aborda desde la óptica financiera y monetaria, pero se rehúye resaltar la visión estructural que hace vislumbrar la pérdida de valor de la moneda nacional como efecto de la débil economía. En la medida que se toquen y ataquen los aspectos que dan lugar a un aparato productivo débil y una estructura comercial distorsionada se podrá también fortalecer la moneda doméstica y al mismo tiempo permitirá comprender mejor la articulación de la base productiva con la función monetaria. Solo la economía puede fortalecer la moneda, la dolarización tolerada es un reflejo de la desconfianza que hay en la política cambiaria y monetaria que se implementa y ejecuta en el país. La incertidumbre por la devaluación genera desconfianza en la moneda nacional, es aquí cuando empresarios, comerciantes y otros sectores económicos empiezan a cotizar y a dolarizar bienes y servicios. La desconfianza y poca credibilidad en la política económica que se impulsa es resultado de la débil economía real y escaza diversificación productiva. Es por la desconfianza que se sustituye la moneda doméstica por la extranjera, en nuestro caso por el dólar en la que distintas transacciones financieras que realiza la gente para obtener productos financieros, bienes o servicios tales como compras, alquileres, depósitos bancarios y otras operaciones se realizan en dólares.
La entrada de divisas al país como efecto de las operaciones con el exterior, principalmente por nuestros excedentes exportables de bienes y servicios, constituyen la fuente principal de ingreso en dólares a la nación, y hoy en día seguido por las remesas familiares que han mostrado un significativo incremento y dan alivio a la economía nacional, pero a la vez significan un costo social expresado en desintegración familiar y sufrimiento de los que son víctima de la migración forzada.

Fortalecer la moneda nacional también implica que se deben desestimular todas las actividades y transacciones u operaciones que no dinamizan la economía. Lo que se necesita es aumentar la producción para cubrir el mercado interno y generar suficientes excedentes para la exportación principal fuente de entrada de divisas. Esto a su vez implica diversificación productiva $y$ búsqueda de nuevos mercados para no depender solo de uno o dos socios comerciales. Actualmente EE.UU. es el principal comprador de nuestros productos, es hacia los EEUU donde van nuestras exportaciones y es de EEUU de dónde vienen nuestras principales importaciones.

Abordar el tema de la dolarización obliga relacionar la moneda extranjera o divisa con algunos conceptos que tienen que ver con el 
dinero y sus funciones. El dinero no solo sirve para facilitar las transacciones, tampoco se puede reducir su función al simple intercambio de comprar y vender, sus funciones son más complejas de lo que se cree o visualiza. No olvidar que los factores de producción tales como el trabajo, los recursos naturales, el capital se remunera con dinero, expresado en salarios, utilidades, interese, dividendos, rentas, etc.

Todo se registra en dinero como acumulador de valor, todo se registra en dinero, aunque este no se exprese físicamente, el sistema financiero todo movimiento de dinero lo registra en el libro contable de su computadora. El que participa en el funcionamiento de la economía registra costos, perdidas, ganancias que a su vez calculan y registran en función del valor del dinero.

Una economía en equilibrio mantiene la complementariedad y contribución mutua entre economía real y economía financiera. Si esto no es así genera distorsión económica. El BCH como autoridad monetaria emite el dinero que entrara en circulación, pero en sí, es el sistema financiero privado o banca comercial la que tiene capacidad de crear dinero. Solo los bancos privados expanden liquidez. Según se lo permita el encaje o reserva legales como instrumento de política monetaria que emplea el Banco Central para controlar el dinero en circulación. Es la autoridad monetaria del Banco Central la que proporciona liquidez de base para todo el sistema y a partir de esa base inyectada los bancos crean dinero.

Diversas son las funciones del dinero, no solo la de medio de cambio, sino que también permite medir cuanta riqueza poseen las personas y cuáles son los elementos de juicio para seguir acumulando riqueza y como orientar los proyectos. Todo esto se da, se sabe y se mide con el dinero. Así procede y sabe cómo actuar el capitalista, la acumulación de riqueza personal y a su vez como se ha de valorar la economía en su conjunto.

En una economía débil como la de Honduras, difícilmente su moneda va a tener aceptación en el exterior, quizá solo sea aceptada al interior del país y en sus fronteras. La condición de divisa se da por su aceptación internacional, es el caso de las monedas fuertes como el dólar, el euro o el yuan. Lo grave del caso es cuando la moneda nacional va perdiendo confianza, los agentes económicos ya no la quieren aceptar para realizar sus operaciones financieras, cuando la moneda doméstica ha perdido credibilidad y la sociedad ha perdido su confianza en ella, entonces el panorama económico se vuelve incierto y trasluce el panorama de la dolarización como esquema monetario. Esto básicamente sucede cuando el país no goza de 
estabilidad económica, cuando el dinero legal del Estado sufre de periódicas devaluaciones, en la que hay incremento del tipo de cambio con relación a la moneda extranjera, sumado a la caída de su valor por presiones inflacionarias. Esta degeneración monetaria e inestabilidad económica es la que da pie para que los ciudadanos opten por sustituir la moneda doméstica por la moneda extranjera, en este caso el dólar (\$). Pero la desconfianza no solo es en la moneda, sino también hay implícitamente una desconfianza en la política económica que se impulsa. Aquí es cuando se empieza a dolarizar, a realizar transacciones en dólares y no solo hablar de dolarización como esquema sino implementando la dolarización, aunque de manera extraoficial, como una forma de prevenir shocks internos, efectos inflacionarios, inestabilidad económica y /o continuas devaluaciones más drásticas.

En tal sentido esta devaluación extraoficial, se está dando no solo por presiones de demanda, sino sobre todo como una forma de tener garantía de que el dinero en poder de los agentes económicos no va a perder su valor, es una medida de seguridad anticipada ante la periódica fluctuación de los principales indicadores y / o variables económicas importantes como los precios, el tipo de cambio, etc. Hay que tener en cuenta que este fenómeno relacionado con la dolarización forma parte de un proceso marcado por un modelo que pone su acento en el comercio para alcanzar el desarrollo. La dolarización por sí misma no genera un clima de confianza y credibilidad, la certidumbre solo puede darse fortaleciendo el aparato productivo y por consiguiente la economía. También la confianza se da en un ambiente de seguridad ciudadana y jurídica de tal forma que este es el ambiente propicio para atraer la inversión, pero no cualquier tipo de inversión, sino aquella que se destine hacia la transformación productiva que implique desarrollo equitativo con justicia social, evitando la inversión especulativa, aquella que, así como entra, sale ante cualquier eventualidad política, social.

De modo que el clima de confianza se da tanto por la seguridad ciudadana, seguridad jurídica, como por la estabilidad económica cuya condición es el fortalecimiento de la economía. Pero la economía se fortalece fortaleciendo el aparato productivo, orientando económicamente la inversión productiva que disminuye los riesgos por el tipo de cambio y la presión sobre los precios. Las divisas que son expresión concreta de las monedas duras entre las que destaca el dólar (\$), hay que generarlos con producción. Sus fuentes principales están en el valor de las exportaciones de bienes y servicios, la inversión extranjera realizada en el país, incluidas la colocación de capitales en el mercado financiero nacional. También están 
el retorno de todos aquellos capitales nacionales ubicados en el exterior y las remesas familiares entre otras.

Estas son entre otras las fuentes de las divisas que entran al país, pero al mismo tiempo el país utiliza divisas para importar bienes $\mathrm{y}$ servicios, pagar el servicio de la deuda. Así mismo como en cualquier economía retorna al exterior inversión extranjera de sus utilidades, también salen capitales nacionales a otras latitudes, y ciudadanos hondureños también envían remesas al exterior. De manera que las divisas que el país posee resultan de restar la entrada de divisas con la salida de las misma, las cuales sirven para acumular las reservas monetarias internacionales y expandir en la economía la liquidez en dólares. Allí está la importancia de dinamizar la economía, fortalecer el aparato productivo, estimular la inversión de manera que se genere empleo y se fortalezca el sector externo que permita eliminar los desequilibrios y mejorar la balanza de pagos. Así se fortalece la economía, así se genera credibilidad en la moneda nacional, así se espanta el fantasma de la dolarización.

Estimular el debate en torno al fenómeno de la dolarización de manera que permita tomar conciencia de las distintas posturas sobre este problema económico de la sustitución de la moneda nacional por la extranjera. Así se podrá tomar conciencia de las ventajas o desventajas que presenta una economía dolarizada. Hay sectores que son favorables a la dolarización argumentando que desaparece el riesgo del tipo de cambio, evitando así la devaluación periódica de la moneda doméstica, en tanto otros sectores se oponen a perder la soberanía monetaria y sus argumentos se basan en el poder de la economía para fortalecer la moneda nacional. De modo que el mejor propósito de abordar este tema es develar las causas y efectos de la dolarización no oficial pero tolerada por la autoridad monetaria y hacer un abordaje profundo en torno a la pérdida de confianza en la moneda nacional por parte de los diversos agentes económicos.

\section{MARCO REFERENCIAL}

El mundo vive y experimenta la gran depresión en los años treinta, inmediatamente después se vive la gran conflagración mundial. La crisis económica mundial se expresa en desempleo, crisis de ingreso, inflación y/o deflación, a partir de esta gran crisis se va vislumbrando la gestación de los dos principales organismos multilaterales de financiamiento el Banco Mundial y el Fondo Monetario Internacional. Antes de que finalizara la segunda guerra mundial, se lleva a cabo en el año 1944 una reunión en Bretton Wood en la que participaron representantes de cuarenta $y$ cuatro países, para firmar el convenio de constitución del FMI, y al mismo tiempo 
crear en esta reunión lo que sería el BM. En esta reunión se debatió sobre la necesidad de propiciar el desarrollo y la estabilidad económica internacional, sobre la base del comercio, el desarrollo para los pueblos y un crecimiento sostenido. En medio del debate surgen dos propuestas la del famoso economista John Maynard Keynes, a quien se le atribuye el haber salvado el capitalismo, con su famosa obra Teoría general de la ocupación, el interés y el dinero, publicada a mediados de la década de los treinta del siglo pasado, también se presenta la propuesta del representante del tesoro de los EE.UU. Ambas propuestas son debatidas en torno a los fines indicados arriba, procurando darle la importancia debida tanto al crecimiento como a la estabilidad económica, sin que esto generara primacía o hegemonía de un país sobre otro. Finalmente se impuso la propuesta del representante del tesoro de EE.UU. -a juzgar por los críticos de la historia de la economía- sobre la base del poderío económico que subyacía en la propuesta misma, y no porque fuera técnicamente superior a la de JM Keynes. Así se crea el FMI como organismo que debía ayudar a los países que tuvieran problemas en su balanza de pagos, pero prevalecía en esta propuesta un sistema monetario en donde la moneda central del sistema sería el dólar. En cambio, Keynes economista ingles gran exponente de la macroeconomía abogaba por la existencia de un organismo multilateral o supranacional similar a como funciona un banco central, para que actuara como cámara de compensación entre los países, tanto en el campo del comercio como en las diversas relaciones financieras internacionales. Así no habría hegemonía. Pero esta propuesta no gusto a los que tenían intereses económicos más allá de la simple estabilidad.

Así es como la moneda que ha prevalecido como divisa de aceptación internacional es el dólar. No obstante, otras monedas fuertes ya forman parte de la canasta de monedas de reserva. Pero la moneda del sistema que priva es el dólar, esto incluso ha dado lugar a conflicto de interese cuando algunos países han querido facturar sus operaciones con otras monedas fuertes.

El esquema dolarizado no está en Honduras, ninguna autoridad monetaria lo ha establecido, pero si algunos agentes económicos prefieren la moneda verde para sus transacciones, todo por garantía de seguridad fututa o por especulación. La autoridad lo permite bajo el argumento de que es el mercado el que establece las reglas del juego sobre la base de la oferta y demanda de los dólares.

La convertibilidad es un principio básico sobre el que recae la capacidad canjeable de las monedas entre países. De ahí la importancia de analizar la relación entre la productividad y la capacidad de que una moneda pueda ser cambiable para 
determinar o diferenciar las llamadas monedas blandas o monedas duras (divisas). La convertibilidad o capacidad de canje de la moneda lo dará el tipo de cambio o su precio, así se mide la equivalencia entre monedas que permite comprender mejor el concepto económico de paridad entre monedas.

Al fin de cuenta se cae en razón de que todo este complejo campo de equivalencia de monedas, es en sí una comparación y/o relación de las economías entre países, o dicho de mejor forma una relación de productividades. El país con mayor productividad su moneda será más fuerte y tendrá más aceptación internacional.

El panorama visible de la dolarización es tan complejo que muchas veces no es fácil comprender. En el intervienen una serie de variables relacionadas no solo con la productividad de las economías o productividad de los factores de producción. También interviene el grado de salidas del sistema financiero determinado por razones financieras positivas, también entran en juego las finanzas públicas, el control fiscal, el conflicto de intereses, la transparencia y las funciones del organismo rector de la política monetaria.

En América Latina se conocen algunas experiencias de dolarización oficial que no es lo mismo con la dolarización extraoficial que se experimenta en Honduras. Está el caso de Ecuador que mantiene el esquema dolarizado aun con el modelo económico que impulsa basado en la mayor participación del Estado en el funcionamiento de la economía, el desarrollo del mercado interno, y el poder ciudadano en la toma de decisiones. Panamá es otro modelo referente de dolarización ese ha sido su esquema por mucho tiempo y Panamá sin embargo es una economía que crece, que tiene óptimos indicadores sociales, sin embargo, indicadores económicos $\mathrm{y}$ sociales favorables no son indicativo de que se debe a la dolarización de su economía. Otro caso es el de El Salvador, donde la dolarización no ha ayudado a la población a salir de la pobreza. El pueblo salvadoreño sobre todo las mayorías no han logrado un nivel óptimo de bienestar con la dolarización ellos mismos dicen "con colones o con dólares seguimos siendo pobres".

\section{METODOLOGÍA}

La investigación se realizó a partir de una serie de preguntas de investigación sobre el tema, en virtud que no se formularon hipótesis básicamente porque no hubo investigación de campo. Prevaleció el enfoque crítico utilizando para ello las herramientas que da la economía política, en este caso la economía política de la dolarización. Se utilizó el método dialectico como parte del método científico, sin menoscabo de los antiguos métodos griegos 
utilizados para llegar a conclusiones sobre la base del análisis y la síntesis, la deducción y la inducción que le dan a la investigación un carácter cualitativo. La bibliografía clásica sobre el tema es poca en virtud de lo cual se cotejo la experiencia vivida en algunos países que mantienen el esquema dolarizado de su economía, pero sobre todo la evidencia empírica de la realidad hondureña que experimenta la cuasi-dolarización por demanda o dolarización extraoficial.

\section{RESULTADOS}

\subsection{Causas de la dolarización}

- La moneda nacional se ha debilitado por las devaluaciones periódicas, generando desconfianza entre los distintos agentes, que los induce a sustituir la moneda doméstica por el dólar.

- La presión sobre el tipo de cambio y la desconfianza en una política monetaria nacional con autonomía e independencia impulsa la sustitución del lempira como moneda de curso legal, por el dólar como medio de pago.

- Se cree que el esquema dolarizado estimula la disciplina fiscal, porque no existiría emisión inorgánica de dinero, lo cual evita las presiones inflacionarias.

- Puede generar un clima de inversión adecuado, sobre todo para la inversión extranjera, cuando por efecto de la dolarización desaparece el riesgo cambiario que evita el problema de la constante devaluación.

\subsection{Efectos de la dolarización}

- Predominio de la moneda extranjera que viene a sustituir la moneda nacional, con lo cual también se pierde soberanía monetaria.

- A partir de la dolarización como esquema monetario, la denominación en dólaresbilletes, monedas y depósitos bancariospasan a constituir la oferta monetaria, cuyo origen siempre será la balanza de pagos.

- Se pierde el valor simbólico que la moneda doméstica representa, lo cual implica pérdida de identidad y mayor dependencia frente al país emisor de la moneda extranjera.

- La política monetaria nacional se modifica y queda bajo la dependencia del país que emite la moneda extranjera.

- Desaparecen las funciones básicas y comunes del banco central y con ello su capacidad de gestión monetaria que le impedirán utilizar los instrumentos de ajuste para evitar los efectos en la economía de los choques internos y externos.

El dinero no es riqueza real, solo es un símbolo de la riqueza real, la verdadera riqueza es la que satisface necesidades humanas. Además, los dólares hay que 
generarlos incrementando la actividad productiva, solo la economía fortalece la moneda, de lo contrario con el esquema dolarizado cualquier desequilibro o shock que sufra la economía estadounidense tendrá serias repercusiones en la economía nacional. Las periódicas devaluaciones generan un ambiente de incertidumbre para las operaciones financieras, la inversión y como medio de corrección de toda distorsión en la economía. Solo impulsando acciones que permitan hacer un adecuado uso de los factores de producción encaminados a desarrollar la actividad económica para incrementar la producción y productividad que ensanche el mercado nacional y a la vez genere excedentes para la exportación, se podrá fortalecer nuestra moneda, si no se hace así, la economía continuará en el rezago $\mathrm{y}$ por consiguiente nuestra moneda continuará debilitándose y perdiendo confianza. Ante una eventual dolarización, que ya se experimenta, aunque de manera no oficial pero permitida, la autoridad monetaria debe analizar la relación entre convertibilidad de la moneda y productividad de los factores de producción, como elemento central para comprender la debilidad o fortaleza de nuestra moneda.

\subsection{Resultados finales}

- La oferta monetaria en dólares constituida en billetes y depósitos bancarios tiene su origen en la balanza de pagos.

- Lo que da valor a la moneda nacional, es la fortaleza de la economía que tiene capacidad de cubrir el mercado interno y genera suficientes excedentes de bienes para el mercado externo.

- El país vive y experimenta una cuasidolarización por demanda que análogamente se le llama dolarización extraoficial, como resultado de la desconfianza en la moneda doméstica y como garantía de seguridad económica para el futuro.

- La dolarización como problema no solo tiene carácter financiero, sino sobre todo tiene su génesis en la economía real que le da un carácter estructural.

- La incidencia del fenómeno de la dolarización no solo gira en torno al tipo de cambio, precios, costos de producción. También incide en la medida que el país va perdiendo soberanía monetaria, en las tasas de interés, inflación y en los movimientos por aumento $\mathrm{o}$ disminución de entrada o salida de divisas que es un elemento fundamental en la dotación de circulante para la economía.

\section{CONCLUSIONES}

Honduras mantiene un déficit crónico en su balanza de pagos, básicamente por su déficit en la balanza comercial. Por lo que la 
disponibilidad de divisas siempre es escasa, aun con la entrada de las remesas familiares

Cuando se depende mucho de una economía fuerte, con moneda igualmente fuerte los agentes económicos empiezan a desconfiar de la moneda doméstica, en el caso de Honduras el lempira va perdiendo no solo valor, sino que también pierde el signo de soberanía y por lo tanto identidad nacional.

Hay tantos bienes y servicios que se compran y/o venden a precios dolarizados, situación que incide negativamente e impacta sobre los ingresos de las personas, porque los sueldos y salarios de estas no son ajustados y reciben su pago en lempiras cada vez más depreciados.

Toda relación de valor entre monedas es una relación entre las economías de países, es una relación de productividades. Así surgen las monedas duras y las monedas blandas, las que tienen aceptación internacional y las que no lo tienen, como es el caso del dólar frente al lempira. El dólar es aceptado en todas partes en tanto que el lempira no cumple las condiciones para ser intercambiado por otras monedas fuera del país, salvo en la frontera común de Honduras y CA.

\section{BIBLIOGRAFÍA}

Doctrina Social de la Iglesia y su aplicación en la economía. Edición autorizada a Fundación Jesús de la Misericordia. FVT 2006.
Havrilesky, Thomas M. Función del dinero en la economía. Editorial Limusa, México, 1973.

Keynes, John Maynard. Teoría general de la ocupación, el interés y el dinero. Fondo de cultura Económica. México DF, 2006.

Marx, Carlos. El capital I: Critica de la Economía Política. Fondo de Cultura Económica, México, cuarta edición, 2014.

Piketty, Thomas. El capital en el siglo XXI. Fondo de Cultura Económica. Argentina, 2015.

Stiglitz, Joseph E. La gran brecha: qué hacer con las sociedades desiguales. Taurus Pensamiento. Barcelona, 2015. 